\title{
Long acting reversible contraceptives utilization and associated factors among women of reproductive age in Arsi Negele town, Southeastern Ethiopia
}

\author{
Desalegn Tsegaw Hibstu ${ }^{1 *}$ (D) and Akalewold Alemayehu ${ }^{2}$
}

\begin{abstract}
Background: Ethiopia is the second populous country in Africa with a total fertility rate of 4.6 and contraceptive prevalence of 35\%, where implant and intrauterine contraceptive devices account for 8 and 2\% respectively. The aim of this study was to determine the magnitude of long acting reversible contraceptives utilization and its associated factors among women of reproductive age in Arsi Negele town, Southeastern Ethiopia.

Methods: Facility-based cross-sectional study was conducted from April 01-May 30, 2017. A total of 361 women using modern contraceptives were selected by a systematic random sampling technique. Pre-tested and interviewer administered structured questionnaire was used to collect quantitative data. Bivariate and multivariate logistic regressions were performed using SPSS version 20.0 software.

Result: The magnitude of long acting reversible contraceptives (LARCS) utilization was 33.5\% [95\% Cl, 28.5-38.8]. Husband with no formal education $[\mathrm{AOR}=0.41, \mathrm{Cl}: 0.16,0.78]$ and unemployed women $[\mathrm{AOR}=0.35, \mathrm{Cl}: 0.42,0.65]$ were negative predictors while having media exposure $[A O R=7.14, \mathrm{Cl}: 3.85,13.25]$, women who desired only one child $[\mathrm{AOR}=3.28, \mathrm{Cl} ; 1.28,8.39]$ and husband support $[\mathrm{AOR}=7.33, \mathrm{Cl}: 3.48,15.43]$ were positive predictors of LARCs utilization.
\end{abstract}

Conclusion: The overall utilization of LARCs is 33.5\%. Creating employment opportunities, male involvement, advertisement and advocacy activities through mass media need to be considered to improve utilization of LARCs.

Keywords: Arsi Negele town, Long acting and reversible contraceptive, Magnitude, Factors

\section{Background}

Long acting reversible contraceptives (LARCs) are birth controls providing effective pregnancy protection for an extended duration without user action. These methods include implants and intrauterine contraceptive devices (IUCDs) [1].

* Correspondence: desuethiopia@yahoo.com

'Department of Reproductive Health, School of Public Health, College of Medicine and Health Sciences, Hawassa University, Hawassa, Ethiopia

Full list of author information is available at the end of the article
Globally in 2017, 12\% of married women were estimated to have an unmet need for family planning. The severity was higher in Africa (22\%) compared to other regions, where the unmet need for family planning is estimated to be as low as $10 \%$ in developed countries [2].

In the developing world, two to three among ten women using oral contraceptives or injectable discontinued within 2 years of use due to side effects, use inconsistency, user run out of the method or other related concerns and as a result majority of women can be benefited if they use LARCs [3]. 
According to the 2007 population census, Ethiopia is the second populous country in Africa next to Nigeria [4] with a total fertility rate of 4.6 and contraceptive prevalence of $35 \%$. Of the total contraceptive utilization, long acting and permanent contraceptive methods account for $10 \%$, IUCD and implant account for 2 and $8 \%$ respectively [5].

Depending on setting, a number of factors have been described in literature to affect adoption of LARCs among contraceptive users. Evidence suggest from other countries and in Ethiopia indicated that desire to more children, opposition to use, lack of knowledge, side effects of contraceptives, age of women, educational status of women and men, and family income are the potential factors affecting utilization of LARCs $[4,6]$.

The Federal Ministry of Health, Ethiopia considered the role of LARCs for birth spacing and limiting, and planned to increase implant and IUD to 33 and 15\% respectively in the method mix by the end of 2020 [7]. In Ethiopia, all contraceptives including long acing and permanent contraceptive methods are rendered free [8]. In the country, many governmental and nongovernmental organizations are delivering LARCs through static and outreach outlets at all levels of health facilities (hospitals, health centers and health posts) [9].

Increasing contraceptive method mix played a big role in reducing discontinuation rates due to short-acting hormonal methods that are primarily chosen by contraceptive users in SSA $[7,10]$ where about 1.8 million unplanned pregnancies would been avoided within 5 years if one-fifth of women utilizing oral contraceptives and injectable shift to LARCs [11]. Therefore, the aim of this study was to determine the magnitude of long acting and permanent contraceptive utilization among women of reproductive age using modern contraceptives in Arsi Negele town, southeastern Ethiopia.

\section{Methods}

\section{Study design and setting}

Facility-based quantitative cross-sectional study was employed from April 01-May 30, 2017. The study was conducted in Aresi Negelle town. The town is located in West Arsi Zone of Oromia regional state in southeastern Ethiopia at a distance of 225 Kilometer) KM from Addis Ababa, capital city of Ethiopia. According to the 2007 Ethiopian population and housing census, the total population of the town was 36,699 (17,618 female) [Arsi Negele town Health Office, Annual report, 2017, Unpublished].

The town has one health center providing preventive, promotive, curative and rehabilitation services for the community and other surrounding communities. The source populations were all women of reproductive age group living in Aresi Negelle town and the study populations were all women of reproductive age group (15-49 years old) using modern contraceptives in Arsi Negele town. However, women who were diagnosed by a physician as seriously ill and unable to hear were excluded.

\section{Sample size determination and sampling procedure}

Sample size was determined using single population proportion formula considering the following assumption: 95\% confidence level $\left(z_{\alpha / 2}^{2}\right)$, 4\% margin of error (d) and expected proportion (p) of long acting reversible contraceptive users was $19.5 \%$ [12].

$$
\frac{n=z_{\alpha / 2}^{2} p(1-p)}{d^{2}}=\frac{(1.96)^{2} \times 0.195(0.805)}{(0.04)^{2}}=376
$$

Study participants were selected using a systematic random sampling technique with an interval of two where the interval constant was obtained by dividing the total modern contraceptive users in the health center to the sample size from their family planning registration book.

\section{Data collection tool and procedure}

Pre-tested and interviewer-administered structured questionnaire, first prepared in English and translated to Amharic language was employed to collect quantitative data. Six registered female nurses were participated to collect the data. Training was given to data collectors for 2 days. The training focused on the study objectives, questionnaire and process of data collection. One bachelor degree holder with principal investigator supervised the data collection process and checked filled questionnaire for consistency and completeness.

\section{Statistical analysis}

After data collection, data were edited and cleaned before analysis, each questionnaire was checked for completeness and code was provided. Data were entered into computer using EPI Info version 3.5.4 and the analysis was done using SPSS version 20.0. Frequency, percentage and descriptive summaries were used to describe the study variables. Logistic regression was carried out to identify factors associated with utilization of LARCs. Variables with $p$-value $\leq 0.2$ in the bivariate analysis were transferred for multivariable logistic regression analysis to control the effect of confounders. Adjusted odds ratios (AOR) with 95\% confidence interval $(\mathrm{CI})$ and $p$-value of less than 0.05 were considered to have significant association between the outcome and the explanatory variables. 


\section{Results}

\section{Socio demographic and economic characteristics}

A total of 361 of reproductive aged women were included in the study. The mean age of the study subjects was 27.4 years $( \pm 4.9$, standard deviation $(\mathrm{SD}))$. Two hundred and twenty seven (62.9\%) study subjects were found in the age group 25-34 years. One hundred and eighty eight $(52.1 \%)$ of the respondents were followers of orthodox religion and 191 (52.9\%) were Oromo by ethnicity. Among the total study participants, 342 (94.7\%) were currently married and about nine in ten, 338 (93.6\%) living in urban area.

One hundred and sixty seven (46.3\%) women had acquired only primary education and 159 (44\%) of all partners had acquired at least a secondary education. As shown in Table 1, about six in ten, (62.3\%) were unemployed and 340 (94.2\%) of their husbands were employed. Almost one among four, 94 (26\%) mothers had monthly income between 1001 and 2000 Ethiopian birr ( $\approx 46$ USD - 93 USD) (Table 1).

\section{Reproductive history of women}

As indicated in table two below, of the total women, about nine in ten women $322(89.2 \%)$ had history of giving birth and 152 (42.1\%) gave more than three live births with $151(41.8 \%)$ alive currently during the study period. One hundred fifty four (42.7\%) women desired to have two and above children in their reproductive life and 109 (30.2\%) wish to have more children within the next 2 years. About three fourth 275 (76.2\%) of the desired number of children was decided jointly (by the husband and wife). The average number of parity,

Table 1 Socio demographic and economic characteristics of the study participants in Arsi Negele town, Southeastern Ethiopia, 2017

\begin{tabular}{|c|c|c|c|}
\hline Variables & Category & Frequency(n) & Percentage (\%) \\
\hline \multirow[t]{3}{*}{ Age in years } & $15-24$ & 100 & 27.7 .9 \\
\hline & $25-34$ & 227 & 62.9 \\
\hline & $>35$ & 34 & 9.4 \\
\hline \multirow[t]{5}{*}{ Ethnicity } & Oromo & 191 & 52.9 \\
\hline & Amhara & 91 & 25.2 \\
\hline & Guraghe & 35 & 9.7 \\
\hline & Tigre & 25 & 6.9 \\
\hline & Wolayita & 19 & 5.3 \\
\hline \multirow[t]{4}{*}{ Religion } & Orthodox & 188 & 52.1 \\
\hline & Protestant & 94 & 26.0 \\
\hline & Muslim & 79 & 21.9 \\
\hline & Catholic & 11 & 3.0 \\
\hline \multirow[t]{2}{*}{ Marital status } & Currently married & 342 & 94.7 \\
\hline & Currently unmarried & 19 & 5.3 \\
\hline \multirow[t]{2}{*}{ Residence } & Urban & 338 & 93.6 \\
\hline & Rural & 23 & 6.4 \\
\hline \multirow[t]{3}{*}{ Women education } & No formal education & 84 & 23.3 \\
\hline & Primary education & 167 & 46.3 \\
\hline & Secondary \& above & 110 & 30.5 \\
\hline \multirow[t]{3}{*}{ Husband /partner education } & No formal education & 59 & 16.3 \\
\hline & Primary education & 143 & 39.6 \\
\hline & Secondary \& above & 159 & 44.0 \\
\hline \multirow[t]{2}{*}{ Women occupation } & Unemployed & 225 & 62.3 \\
\hline & Employed & 136 & 37.7 \\
\hline \multirow[t]{2}{*}{ Husband occupation } & Unemployed & 21 & 5.8 \\
\hline & Employed & 340 & 94.2 \\
\hline \multirow[t]{4}{*}{ Monthly income (Ethiopian Birr) } & $\leq 1000$ & 64 & 17.7 \\
\hline & $1001-2000$ & 94 & 26.0 \\
\hline & $2001-3000$ & 78 & 21.6 \\
\hline & $>3000$ & 125 & 34.6 \\
\hline
\end{tabular}


currently living children, desired number of children in the reproductive life were $2.4(+1.6$ standard deviation $(\mathrm{SD})), 2.3( \pm 1.5 \mathrm{SD})$ and $2.4( \pm 1.3 \mathrm{SD})$, respectively (Table 2).

\section{Contraceptive related characteristics}

As shown in Table 3, of the total modern contraceptives users, nearly four in five women heard about LARCs. Among the total women, 193 (53.5\%) had media exposure about LARCs where $170(88.1 \%)$ were exposed to Television (TV). Injectable contraceptive method was the most known type by women, 338 (93.6\%) and vasectomy was the least known method, 13 (3.6\%). More than two in five, 229 (63.4) women mentioned limiting family size, prevents maternal and child health and child spacing as a benefit of LARCs.

The overall utilization of LARCs among women using modern contraceptive was 121 (33.5\%) [95\% CI, 28.538.8 . Ninety four (26\%) and 27 (7.5\%) women practiced implant and intrauterine contraceptive device (IUCD). Almost four among five, 287 (79.5\%) women had discussion with their husbands on contraceptive utilization and $229(63.4 \%)$ respondents' utilization of contraceptive was approved by their husbands (Table 3 ).

\section{Factors associated with LARC utilization}

As indicated in Table 4, in the multivariate logistic regression analysis; husband education, women occupation, media exposure, desired number of children and approval of partner to use contraceptive were examined to be independent predictors of long acting reversible contraceptive methods.

The study demonstrated that the probability LARCs utilization among women whose husbands with no formal education was $59 \%$ [AOR $=0.41,95 \% \mathrm{CI} ; 0.16,0.78$ ] less likely to adapt LARCs compared with husbands attended secondary and above education. The study identified that practicing LARCs decreased by $65 \%$ among unemployed women compared with employed women $[\mathrm{AOR}=0.35$, CI: 0.42, 0.65].

Another important factor was media exposure to LARCs. Women having media exposure to LARCs were seven times more likely to use LARCs liken with women with no media exposure [AOR $=7.14, \mathrm{CI}: 3.85,13.25]$.

On the other hand, desired number of children and husband approval/support were identified as determinants of LARCs utilization. The odds of using LARCs was nearly three times more likely to be increased among women whose desired number of children was one compared to three and above $[\mathrm{AOR}=3.28$, CI: $1.28,8.39]$. Women who got support/approval from their husband about contraceptive methods were seven times more likely to practice LARCs [AOR $=7.33$, CI: 3.48, 15.43].

\section{Discussion}

In the present study, it was indicated that long acting reversible contraceptives (LARCs) utilization was 33.5\%.

Table 2 Reproductive history of study participants in Arsi Negele town, Southeastern Ethiopia, 2017

\begin{tabular}{|c|c|c|c|}
\hline Variables & Category & Frequency (n) & Percentage $(\%$ \\
\hline \multirow[t]{2}{*}{ History of giving birth } & Yes & 322 & 89.2 \\
\hline & No & 39 & 10.8 \\
\hline \multirow[t]{4}{*}{ Number of ever born births } & None & 39 & 10.8 \\
\hline & One & 74 & 20.5 \\
\hline & Two & 96 & 26.6 \\
\hline & Three and above & 152 & 42.1 \\
\hline \multirow[t]{4}{*}{ Number of alive children } & None & 42 & 11.6 \\
\hline & One & 72 & 19.9 \\
\hline & Two & 96 & 26.6 \\
\hline & Three and above & 151 & 41.8 \\
\hline \multirow[t]{3}{*}{ Desired number of children } & One & 86 & 23.8 \\
\hline & Two & 154 & 42.7 \\
\hline & Three and above & 121 & 33.5 \\
\hline \multirow[t]{2}{*}{ Desire to have more children } & Yes & 109 & 30.2 \\
\hline & No & 252 & 69.8 \\
\hline \multirow[t]{4}{*}{ Decision maker on number of children. } & Woman & 23 & 6.4 \\
\hline & Husband & 34 & 9.4 \\
\hline & Jointly ${ }^{a}$ & 275 & 76.2 \\
\hline & God & 29 & 8.0 \\
\hline
\end{tabular}


Table 3 Contraceptive related characteristics of women of reproductive age groups in Arsi Negele town, Southeastern Ethiopia,

\begin{tabular}{|c|c|c|c|}
\hline Variables & Category & Frequency (n) & Percentage (\%) \\
\hline \multirow[t]{2}{*}{ Heard of LARCs } & Yes & 295 & 81.7 \\
\hline & No & 66 & 18.3 \\
\hline \multirow[t]{2}{*}{ Media exposure to LARCs } & Yes & 193 & 53.5 \\
\hline & No & 168 & 46.5 \\
\hline \multirow[t]{2}{*}{ Type of media exposed } & Television & 170 & 88.1 \\
\hline & Radio & 23 & 11.9 \\
\hline \multirow[t]{7}{*}{ Known contraceptive } & Pills & 301 & 83.4 \\
\hline & Injectable & 338 & 93.6 \\
\hline & Implant & 282 & 78.1 \\
\hline & IUCD & 243 & 67.3 \\
\hline & Condom & 29 & 8 \\
\hline & Tuba ligation & 46 & 18 \\
\hline & Vasectomy & 13 & 3.6 \\
\hline \multirow[t]{5}{*}{ Benefits of LARC ${ }^{a}$} & Limiting family size & 27 & 7.5 \\
\hline & Improves maternal and child health & 13 & 3.6 \\
\hline & Child spacing & 23 & 6.4 \\
\hline & Used for all ${ }^{a}$ & 229 & 63.4 \\
\hline & Don't' know uses & 69 & 19.1 \\
\hline \multirow[t]{2}{*}{ Utilization of LARC } & Yes & 121 & 33.5 \\
\hline & No & 240 & 66.5 \\
\hline \multirow[t]{2}{*}{ Type of LARC used $(n=121)$} & Implant & 94 & 26.0 \\
\hline & IUCD & 27 & 7.5 \\
\hline \multirow[t]{2}{*}{ Contraceptive discussion among couples } & Yes & 287 & 79.5 \\
\hline & No & 69 & 20.5 \\
\hline \multirow[t]{2}{*}{ Approval of husband to use contraceptive } & Yes & 229 & 63.4 \\
\hline & No & 132 & 36.6 \\
\hline
\end{tabular}

Used for alla: indicate benefits of LARC for limiting family size, improves maternal and child health and child spacing

This finding was nearly in line with a study conducted in Ethiopia: Areka town (29.7\%) and Adigrat town (37.3\%) $[13,14]$ and higher than studies done in Ethiopia: Debremarkos (19.5\%) and Mekelle (12\%) [12, 15]. The increased prevalence noticed in this research might be due to the difference in time and study setting (institutional versus community based) and, improved awareness of women and advocacy of long acting and permanent contraceptives by governmental and non-governmental organization through mass media and health professionals.

The most widely used long acting reversible contraceptive method in this study was implant (26\%). This result was similar with other findings in Ethiopia: Arbaminch and west Ethiopia, [16, 17]. Only 7.5\% of the study participants practiced intrauterine contraceptive (IUCD) device which is nearly similar with a study conducted in Nigeria (7\%) [18], and lower than the findings in Indonesia (52\%) [19]. The possible explanation in this study could be women might have misconception about IUCD and its side effects such as interference with sexual intercourse, cancer, delays pregnancy, restriction from working normal activity and invasion of privacy during its insertion and removal [15].

In the current study, it was figured out that utilization of LARCs was higher among women whose husbands completed secondary and above education compared with women who did not attend formal education. This finding is agreed with studies in Ethiopia: Adigrat town and west Ethiopia $[14,17]$. This might be explained by the fact that there is no question that better educated family members would have access for information on LARC methods and their increased knowledge on modern contraceptives. It is also thought that increased educational status in particular secondary education and above could have a positive outcome service use and female decision-making power on reproductive health services including family planning. 
Table 4 Multivariate logistic regression model predicting utilization of LARCs among women in Arsi Negele town, Southeastern Ethiopia, 2017

\begin{tabular}{|c|c|c|c|c|c|c|}
\hline \multirow[t]{2}{*}{ Variables } & \multirow[t]{2}{*}{ Category } & \multicolumn{2}{|c|}{ Use of LARC } & \multirow[t]{2}{*}{${ }^{*} \mathrm{COR}^{*}(95 \% \mathrm{Cl})$} & \multirow[t]{2}{*}{$\mathrm{AOR}^{*}(95 \% \mathrm{Cl})$} & \multirow{2}{*}{$\begin{array}{l}\boldsymbol{P} \text { - } \\
\text { value }\end{array}$} \\
\hline & & No & Yes & & & \\
\hline \multirow[t]{3}{*}{ Age of women (years) } & $15-24$ & 79 & 21 & $0.30(0.13,0.68)$ & $0.44(0.14,1.36)$ & 0.154 \\
\hline & $25-34$ & 143 & 84 & $0.66(0.32,1.37)$ & $0.50(0.19,1.35)$ & 0.171 \\
\hline & $\geq 35$ & 18 & 16 & 1.00 & 1.00 & \\
\hline \multirow[t]{3}{*}{ Husband education } & No formal education & 47 & 12 & $0.48(0.24,0.99)$ & $0.41(0.16,0.78)$ & 0.006 \\
\hline & Primary education & 89 & 54 & $1.15(0.72,1.84)$ & $0.75(0.65,0.98)$ & 0.005 \\
\hline & Secondary and above & 104 & 55 & 1.00 & 1.00 & \\
\hline \multirow[t]{2}{*}{ Women occupation } & Unemployed & 162 & 63 & $0.52(0.33,0.82)$ & $0.35(0.42,0.65)$ & 0.001 \\
\hline & Employed & 78 & 58 & 1.00 & 1.00 & \\
\hline \multirow[t]{2}{*}{ Heard of LARCs } & Yes & 180 & 115 & $6.39(2.67,15.27)$ & $1.50(0.53,4.29)$ & 0.450 \\
\hline & No & 60 & 6 & 1.00 & & \\
\hline \multirow[t]{2}{*}{ Media exposure to LARCs } & Yes & 89 & 104 & $10.38(5.84,18.46)$ & $7.14(3.85,13.25)$ & 0.002 \\
\hline & No & 151 & 17 & 1.00 & 1.00 & \\
\hline \multirow[t]{2}{*}{ Desire for more children } & Yes & 81 & 28 & $0.59(0.36,0.97)$ & $0.73(0.38,1.38)$ & 0.329 \\
\hline & No & 159 & 93 & 1.00 & 1.00 & 1.00 \\
\hline \multirow[t]{3}{*}{ Desired number of children } & One & 46 & 40 & $4.14(2.20,7.80)$ & $3.28(1.28,8.39)$ & 0.023 \\
\hline & Two & 94 & 60 & $3.04(1.72,5.38)$ & $2.58(1.16,5.71)$ & 0.020 \\
\hline & Three and above & 100 & 21 & 1.00 & 1.00 & \\
\hline \multirow[t]{2}{*}{ Discussion among couples } & Yes & 81 & 28 & $2.55(1.36,4.78)$ & $0.493(0.14,1.69)$ & 0.261 \\
\hline & No & 159 & 93 & 1.00 & 1.00 & \\
\hline \multirow[t]{2}{*}{ Husband Support to use contraceptive } & Yes & 118 & 111 & $2.55(1.36,4.78)$ & $7.33(3.48,15.43)$ & 0.000 \\
\hline & No & 122 & 121 & 1.00 & 1.00 & \\
\hline
\end{tabular}

The study also revealed that utilization of LARC was increased among employed women than unemployed women. This finding was consistent with studies in Ethiopia: Adigrat town and west Ethiopia $[14,17]$. This could happen because employed women would have a positive outcome in utilization of LARC by having frequent health institution contact to access the service with payment though it is provided free of charge in Ethiopia.

Significant association was observed concerning media exposure. It was figured out that utilization of LARC was more likely to increase among women had exposure of media. This finding is in line with study conducted in Ethiopia [17]. This could be explained as media has a power in explaining the different methods available, their benefits and where the methods are available and enhances women to utilize the methods.

On the other hand, desired number of children and approval of husband/partner plays significant role on utilization of long acting and permanent contraceptive. Women whose desired number of children only one were more likely to use LARC. Women who had approval from their husband/partner were more likely to use LARC. This finding was congruent with the studies done in Ethiopia: Debremarkos, Arbaminch and Butajira [12, 16, 20].

\section{Limitations}

When interpreting the findings of this study, researchers need to consider the following limitations. First, the cross sectional nature of the data had made impossible to arrive at the causal relation between the different explanatory variables and knowledge of long acting and permanent contraceptives. Second, as the study is based on a sample of all reproductive age group women who are using modern contraceptives, possible selection bias needs to be seen since it did not address the main characteristic of the general population in the study.

\section{Conclusions}

In general, in this study, the magnitude of long acting reversible contraceptive was 33.5\%. Husband education, women occupational status, media exposure, desired number of children and approval of husband/ partner to use contraceptives were predictors of 
LARCs among women in Arsi Negele town, Southeastern Ethiopia.

Creating employment opportunities, male involvement, advertisement and advocacy activities through mass media need to be considered to improve utilization of LARCs.

\section{Abbreviations}

AOR: Adjusted odd ratio; Cl: Confidence Interval; EDHS: Ethiopian Demographic and Health Survey; IUCD: Intra-uterine device; KM: Kilometer; SD: Standard deviation; LARC: Long acting reversible contraceptive; SSA: Sub Saharan Africa; SPSS: Statistical Package Software for Social Sciences

\section{Acknowledgements}

Arsi Negele town health office should be acknowledged for facilitating the data collection process. The study subjects need to be given respect, without their consent and the provision of the demanded information, this research work would not have been come into existence.

\section{Authors' contributions}

DTH took part in planning and designing the study, monitoring data collection process and analyzes the data. AA participated in planning the study, supervising data collection process and writing the manuscript. Both authors read and approved the final manuscript.

\section{Funding}

No funding.

\section{Availability of data and materials}

The data that support the findings of this study will be available from the corresponding author upon reasonable request in the form of statistical package for social sciences (SPSS) spread sheet.

\section{Ethics approval and consent to participate}

Ethical clearance was taken from the ethical clearance Institutional Review Board of Hawassa University, College of Medicine and Health Sciences. Supportive letter was secured from Arsi Negele town health office. The study participants were informed about the purpose of the study and informed verbal and written consent was taken.

\section{Consent for publication}

Not applicable.

\section{Competing interests}

The authors declare that they have no competing interests.

\section{Author details}

'Department of Reproductive Health, School of Public Health, College of Medicine and Health Sciences, Hawassa University, Hawassa, Ethiopia. ${ }^{2}$ Department of Epidemiology, School of Public Health, College of Medicine and Health Sciences, Hawassa University, Hawassa, Ethiopia.

Received: 9 July 2019 Accepted: 14 May 2020

Published online: 01 June 2020

\section{References}

1. Stoddard A, McNicholas C, Peipert JF. Efficacy and safety of long-acting reversible contraception. Drugs. 2011 May 1;71(8):969-80.

2. United Nations, Department of Economic and Social Affairs, Population Division. Model-based estimates and projections of family planning indicators 2017. New York: United Nations; 2017b.

3. Ali M, Cleland J. Determinants of contraceptive discontinuation in six developing countries. J Biosoc Sci. 1999 Jul;31(3):343-60.

4. Federal Democratic Republic of Ethiopia, Planning and Programming Department, Ministry of Health Of Ethiopia. Health and health related indicators. Addis Ababa; 2007.

5. Demographic E. Health survey: Addis Ababa. Ethiopia and Calverton Maryland, USA: central statistics agency and ORC macro; 2016. p. 2016.

6. Lauro D. Abortion and contraceptive use in sub-Saharan Africa: how women plan their families. Afr J Reprod Health. 2011;15(1).
7. Federal Democratic Republic of Ethiopia Ministry of Health. HSTP Health Sector Transformation Plan 2015/16-2019/20 (2008-2012 EFY). 2015.

8. Ministry of Health Ethiopia, PMNCH, WHO, World Bank, AHPSR, Participants in the Ethiopia multi-stakeholder policy review (2015). Success Factors for Women's and Children's Health: Ethiopia. 2015.

9. Federal Democratic Republic of Ethiopia Ministry of Health. National Guideline for family planning Services in Ethiopia. 2011.

10. Scott A, Glasier A. Evidence based contraceptive choices. Best Pract Res Clin Obstet Gynaecol. 2006 Oct 1;20(5):665-80.

11. Hubacher D, Mavranezouli I, Mc GE. Unintended pregnancy in subSaharan Africa: magnitude of the problem and potential role of contraceptive implants to alleviate it. Contraception. 2008;78(1):73-8.

12. Bulto GA, Zewdie TA, Beyen TK. Demand for long acting and permanent contraceptive methods and associated factors among married women of reproductive age group in Debre Markos town, north West Ethiopia. BMC Womens Health. 2014 Dec 1;14(1):46.

13. Kabalo MY. Utilization of reversible long acting family planning methods among married 15-49 years women in Areka town, Southern Ethiopia. Int J Sci Rep. 2016;2(1):1-6.

14. Gebreyesus B, Berhe S, Bayray A. Assessment of long acting and permanent contraceptive method utilization and associated factors among married women of reproductive age group in Adigrat town. Tigray Reg Ethiop. 2015;2:36-45

15. Alemayehu M, Belachew T, Tilahun T. Factors associated with utilization of long acting and permanent contraceptive methods among married women of reproductive age in Mekelle town, Tigray region, North Ethiopia. BMC Pregnancy Childbirth. 2012 Dec;12(1):6.

16. Gultie T, Hailu D, Workineh Y. Predictors of long acting contraceptives utilization among reproductive age women in Arba Minch Zuria district, Ethiopia. Qual Prim Car. 2016;24(1):17-22.

17. Melka AS, Tekelab T, Wirtu D. Determinants of long acting and permanent contraceptive methods utilization among married women of reproductive age groups in western Ethiopia: a cross-sectional study. Pan Afr Med J. 2015;22(1).

18. Chigbu B, Onwere S, Aluka C, Kamanu C, Okoro O, Feyi-Waboso PJ. Contraceptive choices of women in rural Southeastern Nigeria. Niger J Clin Pract. 2010;13(2).

19. Schoemaker J. Contraceptive use among the poor in Indonesia. Int Fam Plan Perspect. 2005;1:106-14

20. Mekonnen W, Worku A. Determinants of low family planning use and high unmet need in Butajira District, South Central Ethiopia. Reproductive Health. 2011;8(1):37.

\section{Publisher's Note}

Springer Nature remains neutral with regard to jurisdictional claims in published maps and institutional affiliations.
Ready to submit your research? Choose BMC and benefit from:
- fast, convenient online submission
- thorough peer review by experienced researchers in your field
- rapid publication on acceptance
- support for research data, including large and complex data types
- gold Open Access which fosters wider collaboration and increased citations
- maximum visibility for your research: over $100 \mathrm{M}$ website views per year
At BMC, research is always in progress.
Learn more biomedcentral.com/submissions 